\title{
Tingkat kesadaran dan pengetahuan pemilik anjing di kota Malang mengenai infestasi ektoparasit
}

\author{
Tiara Widyaputri*, Nurina Titisari, Rahadi Swastomo \\ Fakultas Kedokteran Hewan, Universitas Brawijaya, Kota Malang, Jawa Timur
}

\begin{abstract}
ABSTRAK: Anjing dan kucing merupakan hewan yang paling banyak dipelihara sebagai hewan kesayangan sebagaimana masyarakat di kota Malang. Ektoparasit seperti caplak dan pinjal seringkali menyerang anjing sehingga menyebabkan gangguan kesehatan baik pada anjing maupun pemiliknya. Pemeriksaan terhadap infestasi ektoparasit pada anjing sedianya dilakukan secara rutin. Kegiatan pengabdian masyarakat berupa pemeriksaan ektoparasit dan pemberian obat anti-ektoparasit yang dilakukan di Pawvillion dog cafe, Kota Malang dan didatangi oleh 18 orang pemilik anjing dengan total anjing yang diikutsertakan sebanyak 35 ekor. Hasil pemeriksaan ektoparasit ditemukan 2 jenis ektoparasit yaitu caplak dan pinjal. Anjing sebanyak 16 ekor telah terinfeksi ektoparasit spesies Ripichephalus sp. dan 3 ekor anjing terinfeksi pinjal Ctenocephalides sp. Evaluasi kuesioner yang telah diisi oleh pemilik anjing, diketahui bahwa pemberian obat kutu dan pembersihan lingkungan masih jarang dilakukan. Para pemilik anjing diberi selebaran berisi informasi mengenai ektoparasit sebagai media edukasi mengenai pentingnya menghindarkan anjing dari infestasi ektoparasit.

Kata kunci:

anjing, ektoparasit
\end{abstract}

\section{- PENDAHULUAN}

Manusia dan hewan sudah menjalin hubungan sejak lama. Manusia memelihara hewan dengan tujuan yang saling menguntungkan secara emosinal. Anjing sudah dikenal selama ratusan tahun sebagai hewan yang mampu berinteraksi dengan manusia (Affandi et al. 2015). Anjing yang memiliki ektoparasit di tubuhnya beresiko mengalami reaksi alergi hingga terinfeksi berbagai penyakit yang dapat mengancam jiwa anjing bahkan mengganggu kesehatan pemiliknya (Araes-Santos et al. 2015, Starkey \& Stewart 2015). Pengabdian masyarakat ini dilakukan dengan tujuan agar pemilik anjing mengetahui informasi mengenahi ektoparasit dan bahayanya sehingga dapat meningkatkan kesadaran pemilik untuk menghindarkan anjing peliharaan mereka dari infestasi ektoparasit.

\section{- BAHAN DAN METODE}

Penelitian dilakukan dalam kegiatan pengabdian kepada masyarakat yang dilaksanakan di Pawvillion Dog Cafe, Kota Malang, Jawa Timur. Kegiatan yang dilaksanakan melalui pemeriksaan keberadaan ektoparasit pada anjing dan pemberian obat antiektoparasit. Pemilik anjing diminta untuk mengisi kuesioner mengenai ektoparasit. Pemilik anjing juga diberi informasi melalui selebaran yang berisi informasi mengenai ektoparasit anjing.

Pemeriksaan Ektoparasit: Anjing yang datang didaftar dan diperiksa kesehatannya oleh tim dokter pemeriksa. Pemeriksaan dilakukan secara menyeluruh dengan fokus untuk melihat ada atau tidaknya ektoparasit pada tubuh anjing. Ektoparasit yang ditemukan kemudian diidentifikasi.

Analisis Data: Data didapatkan melalui wawancara dengan pemilik anjing untuk mengisi kuesioner. Kemudian data ditabulasi menggunakan microsoft excell dan dianalisis secara deskriptif.

\section{- HASIL DAN PEMBAHASAN}

Pawvillion Dog Cafe merupakan restoran yang mengijinkan pengunjung untuk membawa anjing kesayangannya. Selain itu, Pawvillion Dog Cafe juga memelihara anjing yang disediakan khusus untuk bermain dengan para pengunjung yang datang ke cafe.
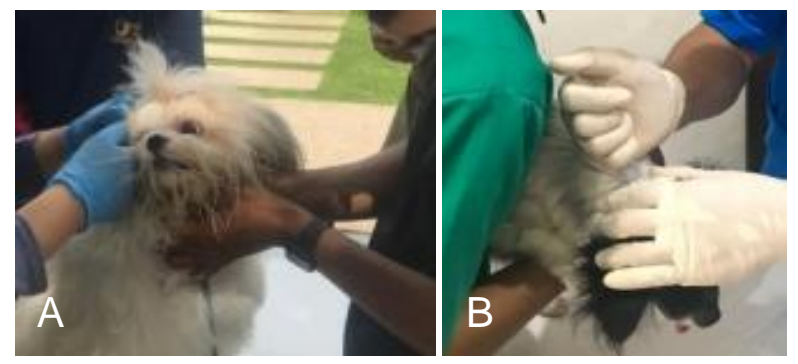

Gambar 1 Kegiatan pengabdian masyarakat. (A) Pemeriksaan dan konsultasi serta (B) pemberian obat antiektoparasit

Diterima: 05-11-2018 | Direvisi: 26-11-2018 | Disetujui: 30-11-2018 () 2018 CC-BY-SA. Ini adalah artikel Open Access yang didistribusikan berdasarkan ketentuan dari Creative Commons Attribution ShareAlike 4.0 International License (https://creativecommons.org/licenses/by-sa/4.0/). 
Pemilik anjing sebanyak 18 orang membawa anjingnya dengan total 35 ekor untuk mengikuti kegiatan pemeriksaan dan pemberian obat ektoparasit ini. Pemilik berkonsultasi dengan dokter serta mengisi kuesioner seputar pengetahuan mereka tentang ektoparasit disaat proses pemeriksaan dilakukan (Gambar 1). Hanya 13 dari 18 orang pemilik yang bersedia mengisi kuesioner.

Hasil pemeriksaan diketahui bahwa sebanyak 16 ekor dari 35 ekor anjing memiliki ektoparasit. Ektoparasit kemudian diidentifikasi sebagai Ripicephalus sp. dan Ctenocephalides sp. Gambar 2A menunjukkan bahwa $69,2 \%$ pemilik anjing mengetahui bahwa anjingnya pernah mengalami infestasi parasit. Namun hal ini tidak memberi kesadaran kepada pemilik yang sebagian besar tidak pernah memberikan antiektoparasit kepada anjing mereka (Gambar 2B).
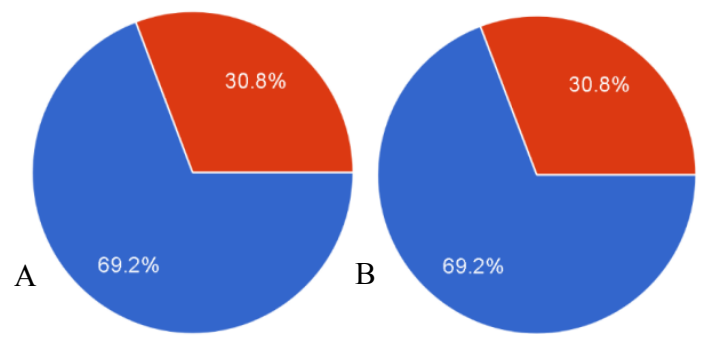

Gambar 2 (A) Persentase anjing yang pernah mengalami infestasi ektoparasit dan (B) persentase pemberian obat antiektoparasit pada anjing. Keterangan: merah=tidak pernah, biru=pernah.

Infestasi ektoparasit memberikan rasa tidak nyaman bahkan dapat menjadi vektor berbagai penyakit baik bagi hewan maupun manusia. Gangguan yang ditimbulkan mulai dari gangguan kulit sampai penyakit sistemik dan ganguan jantung (Agbolade et al. 2008, Salant et al. 2013). Ripicephalus sp. dan Ctenocephalides sp. merupakan ektoparasit jenis caplak dan pinjal yang paling sering menyerang anjing dan kucing (Romanita et al. 2012). Caplak menggigit dan menghisap darah anjing. Caplak dapat menyebabkan anemia sampai imunosupresi. Selain itu, caplak juga dapat memindahkan mikroorganisme patogen ke tubuh anjing sehingga akan mengakibatkan gangguan yang lebih serius seperti erlichiosis (Elsheika 2017). Erlichiosis pada anjing sering disebabkan oleh bakteri E. canis yang menyerang sel darah putih anjing. Erlichiosis pada anjing juga sering disebut dengan "demam berdarah". Hal terpenting yang harus dilakukan adalah mengontrol penyebaran caplak di lingkungan (Straube 2010). Anjing yang alergi terhadap gigitan caplak dapat menunjukkan gejala diantaranya kemerahan, kerontokan rambut dan kerusakan rambut (ESCCAP 2012).

Pemilik berkonsultasi dengan dokter pemeriksa selama diskusi dan pengisian kuesioner. Informasi berupa selebaran diberikan untuk meningkatkan kewaspadaan pemilik terhadap ektoparasit. Seluruh anjing yang terinfeksi dan anjing yang tidak terinfeksi diberikan antiektoparasit oleh dokter hewan pemeriksa. Para pemilik diharapkan sudah memiliki cukup pengetahuan dari proses konsultasi dan selebaran informasi yang dibagikan sehingga tumbuh kesadaran untuk rutin memeriksakan anjing yang dimilikinya dan memberikan obat anti kutu (antiektoparasit) di dokter hewan.

\section{- SIMPULAN}

Sebagian besar pemilik anjing sudah mengetahui bahwa infestasi ektoparasit pernah terjadi pada anjingnya, akan tetapi pemilik tidak memberikan antiektoparasit. Selebaran yang berisi informasi mengenai ektoparasit dan bahayanya pada anjing diharapkan mampu meningkatkan kesadaran pemilik dan dapat menekan infestasi parasit pada anjing.

\section{— INFORMASI PENULIS}

Penulis untuk Korespondensi

*TW: tiarawidyaputridrh@gmail.com

Fakultas Kedokteran Hewan, Universitas Brawijaya, Malang

\section{- UCAPAN TERIMA KASIH}

Penelitian ini merupakan bagian dari kegiatan pengabdian masyarakat yang dilaksanakan melalui kerjasama dengan Pawvillion Dog Cafe dan didanai oleh dana pengabdian masyarakat DPPSPP Fakultas Kedokteran Hewan Universitas Brawijaya.

\section{- PUSTAKA ACUAN}

Affandi SW, Ferasyi TR, Nurliana, Manaf ZH, Sulasmi, Razali. 2015. Akurasi perkiraan populasi anjing liar sebagai risiko hewan penular rabies di empat kecamatan kota Banda Aceh menggunakan software APSP. Jurnal Medika Veterinaria. 9(2): 131-134.

Agbolade OM, Soetan EO, Awesu A. Ojo JA, Somoye OJ, Raufu ST. 2008. Ectoparasites of domestic dogs in some ijebu communities, Southwest Nigeria. World Applied Sciences Journal. 3(6): 916-920.

Araes-Santos AI, Moraes-Filho J, Peixoto RM, Spolidorio MG, Azevedo SS, Costa MM, Labruna MB, Horta MC. 2015. Ectoparasite infestations and canine infection by Rickettsiae and Erlichiae in a semi-arid region of Norteastern Brazil. Vectorborne and Zoonotic Disease. 15(1): 645-651.

European Sientific Counsel Companion Animal Parasites [ESCCAP]. 2012. Control of Ectoparasites in Dogs and Cats. Worchestershire: ESCCAP

Elsheika H. 2017. Ectoparasites: preventive plans and innovations in treatment. [tersedia pada https://www.vettimes.co.uk (diunduh 5 Juni 2018)].

Romanita M, Poliana T, Mateescu C. 2012. Study concerning ectoparasites infestation in dogs and cats in the TargovisteDambovita area. Scientific Works-University of Agronomical Sciences and Veterinary Medicine, Bucharest Series C, Veterinary Medicine 58(4): 262-271.

Salant H, Mumcuoglu KY, Baneth G. 2013. Ectoparasites in urban stray cats in Jerussalem, Israel: differences in infestation patterns of fleas, ticks and permanent ectoparasites. Medical and Veterinary Entomology. 28(3), 314-318.

Starkey L, Stewart J. 2015. Feline arthropods. Todays Veterinary Practice Journal. January/February: 59-64

Straube J. 2010. Canine Erlichiosis-from Acute Infection to Chronic Disease [tersedia pada www.cvbd.org (diunduh 30 November 2018)]. 